\title{
Energy consumption analysis of a ground water-source heat pump for the plant factory based on TRNSYS simulation
}

\author{
Gukun Yang ${ }^{1, a}$, Huixian Shi ${ }^{1, *}$, DeTian Xu${ }^{1}$, Zheng Shen ${ }^{1}$, Zhonghua Zhang ${ }^{1}$, Haowen Shen ${ }^{1}$, Zijing Wang ${ }^{1}$ \\ ${ }^{1}$ New rural development institute of Tongji University, National Engineering Research Center of Protected Agriculture, Shanghai, China
}

\begin{abstract}
The ground water-source heat pump system for the plant factory lacks a scientific operation strategy to solve the problem of high energy consumption in winter and summer. It is very difficult and uneconomical to change the operation conditions by experimental means to obtain actual operation data. The current study aims to build a TRNSYS simulation model of the ground water-source heat pump system of Shanghai Chongming Natural Light Plant Factory. For the heating season, the simulation of energy consumption was 2315 GJ. Compared with the actual energy consumption, the relative error is $-0.98 \%$, which indicates that the simulation results are accurate and the simulation model developed is appropriate and usable. Numerical simulations for the whole year on this basis yielded that the plant factory energy supply system operates from November to March with a heating energy consumption of 3530.84 GJ and from June to September with a cooling energy consumption of 1126.24 GJ. In most cases, the indoor temperature fluctuates within a reasonable range, but in the summer high-temperature season, the plant factory temperature will reach above $40^{\circ} \mathrm{C}$, which seriously affects plant growth. After optimization, the plant factory stops production in July and August, and the system stops running, the results are that the optimized system can save $56 \%$ of the annual cooling energy consumption, totalling $767.48 \mathrm{GJ}$, which can reduce the costs by 160,318.05 RMB.
\end{abstract}

\section{Introduction}

The ground water-source heat pump system is highly efficient and environmentally friendly [1]. Research on the application of ground water-source heat pump technology in the plant factory sector is relatively extensive, focusing on system design [2,3], system performance [4], technical and economic feasibility [5], operational effectiveness [6], and thermodynamic analysis [7].

Since it is time-consuming and expensive to change the operating conditions by experimental means, some scholars have tried to use numerical calculation methods and TRNSYS software to carry out simulation studies [8]. TRNSYS (Transient System Simulation) software is a transient system simulation program that is widely used in the construction industry due to the performance benefits of simulation calculations and the ease of modular operation. Andrew [9] et al. used the TRNSYS for the first time to simulate a solar collector-assisted ground source heat pump heating system for six US cities in different climate zones over 20 years. The results show that hybrid ground source heat pump systems with solar collectors are significantly more energy-efficient in predominantly heating areas. Shi [10] et al. used TRNSYS software to simulate a solar-ground source heat pump system for heating biogas digester and obtained the following results for a typical day and a whole year. On a typical day in winter, the total heat supply is $225.52 \mathrm{MJ} /$ $\mathrm{d}$. The total heat consumption amounts to $208.57 \mathrm{MJ} / \mathrm{d}$.

It is necessary to mention that TRNSYS simulation studies based on ground source heat pump are mainly focused on the fields of construction and biogas engineering, while there are fewer studies on plant factories. This paper is based on the study of the Chongming natural light plant factory to simulate the energy consumption of ground water-source heat pump system by TRNSYS software for a typical year throughout the year and optimize the operation strategy.

\section{Principle of the ground water-source heat pump}

The plant factory covers 21,000 square meters, consisting of three zones A, B, and C. Zone A consists of seven greenhouses and uses a water-storage ground source heat pump system for energy supply. Each greenhouse is $35.2 \mathrm{~m}$ long and $24 \mathrm{~m}$ wide, divided into six spans, with a truss height of $7 \mathrm{~m}$ and a roof angle of $22^{\circ}$. A double-layer shading curtain system and internal thermal insulation curtain are arranged on the roof, which is used to block the sun in high temperature in summer and keep warm in winter. The plant factory also contains a heating (cooling) system, a fan system, and a ventilation system. The temperature, humidity, $\mathrm{CO}_{2}$ concentration, light, and other environments can be changed according to the needs of plant growth. There are a ground water-source heat

*Corresponding author e-mail: huixian_shi@tongji.edu.cn, ${ }^{a} 987798459 @ q q . c o m$ 
pump and an energy storage tank in the plant factory, as shown in Figure 1.

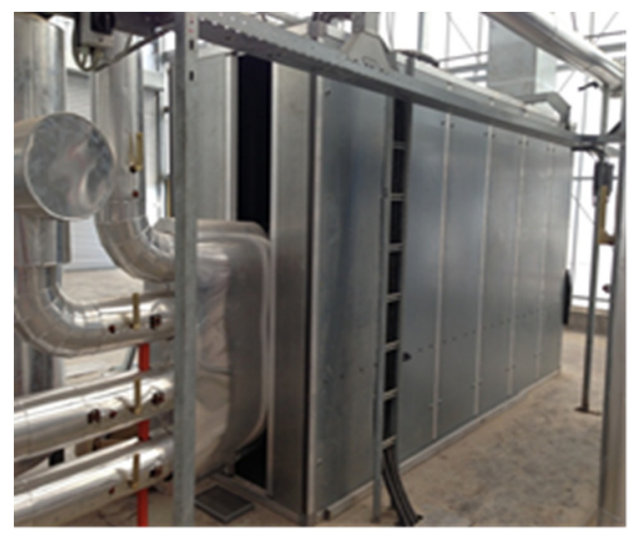

a.Heating pump equipment

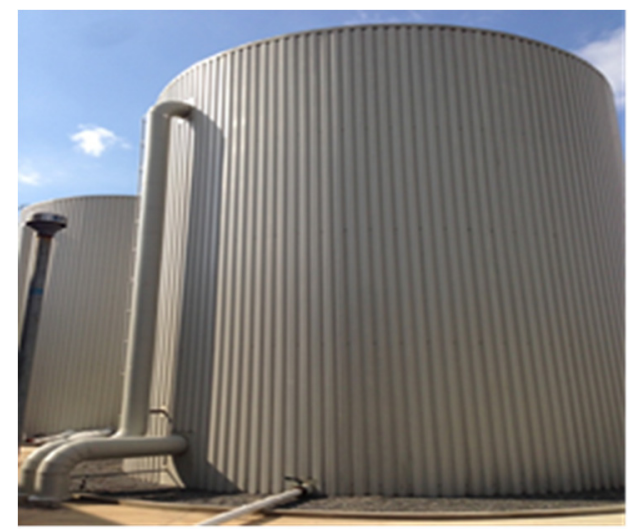

b. Hot water tank

Figure 1. The heat pump system equipment.

In actual operation, the selection of the operation mode of the energy supply system is governed by different external factors such as the heat (cooling) load of the plant factory, the amount of heat (cooling) supplied by the unit, the price of electricity, the average temperature of the storage tank, etc. The matching relationship between the output power of the unit on the supply side and the heat (cooling) load of the plant factory on the demand side determines the operation mode of the unit. The ground water-source heat pump system of the plant factory has the following five modes of operating: (1) When the electricity price is low and the heating (cooling) capacity of the system is greater than the required load of the greenhouse, the unit will supply heat (cooling) while storing heat (cooling). (2) When both the heat pump system and the heat storage (cooling) tank can't reach the required load of the greenhouse, the heat storage (cooling) tank and the unit will supply heat (cooling). (3) When the electricity price is at its peak, the heat storage (cooling) tank will be used to supply heat (cooling). (4) When the heat pump unit stops running, the cold water well will be used to store cold. (5) In summer, when the temperature of the cold water well is less than $12{ }^{\circ} \mathrm{C}$, the cold water well will be used to supply cold directly.

\section{The simulation models}

The TRNSYS model was constructed for the characteristics of ground water-source heat pump systems. The modules of the TRNSYS simulation model for the system contain meteorological parameters, regional buildings, and sky temperature, etc. Typical annual weather data from Shanghai weather stations were selected for simulation. A comparison of typical annual outdoor temperatures at Shanghai weather data collection stations from January to March and outdoor temperatures at the plant factory is shown in Figure 2. As can be seen in Figure 2, there is a small variation in the difference between the hourly outdoor temperature data recorded by the Shanghai weather data collection station for the heating season and the hourly outdoor temperature data recorded by the plant factory. The average outdoor temperature recorded by the statistical weather station for January to March was $7.0^{\circ} \mathrm{C}$ and the average outdoor temperature recorded by the plant factory for January to March was $6.7^{\circ} \mathrm{C}$, a difference of $0.3^{\circ} \mathrm{C}$. The minimum temperature at the weather station approximates the minimum temperature at the plant factory, which is approximate $-3^{\circ} \mathrm{C}$. When the minimum temperature is used to calculate the maximum heat load, the error is small and therefore the typical annual meteorological parameters of the weather station are valid and can be used for numerical simulations. The simulation of energy consumption from January to March shows that the actual energy consumption value of the plant factory from January to March is 2337.95 GJ and the simulated energy consumption value of the plant factory from January to March is 2315.16 GJ. The relative error between the two is $-0.98 \%$, which is a small error because the difference between the average temperature in a typical year and the actual temperature from January to March is only $0.3^{\circ} \mathrm{C}$ and the lowest temperature is about $-3^{\circ} \mathrm{C}$, so the overall The error is small. It is concluded that the TRNSYS simulation of the plant factory during the heating season can quantify the energy consumption of the plant factory during the heating season, and the TRNSYS model, as well as the meteorological parameters, can be used to simulate energy consumption throughout the year.

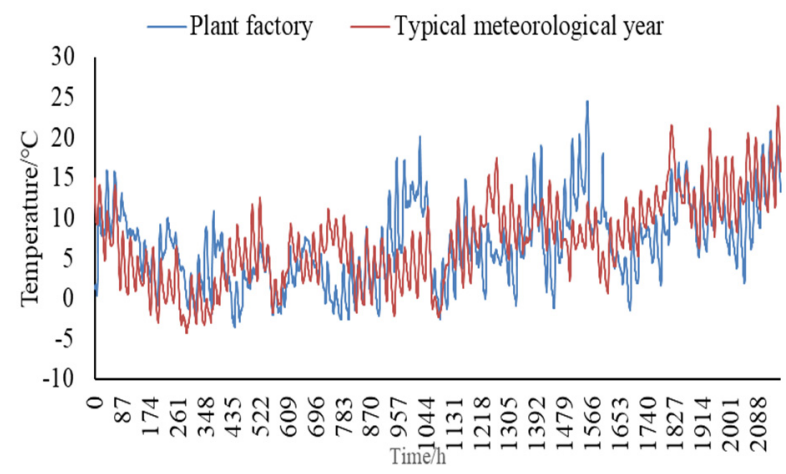

Figure 2. Comparison of typical meteorological outdoor temperature of Shanghai Meteorological

In the TRNSYS simulation model of plant factory energy supply system, the parameters and heating season parameters of the ground water-source heat pump energy 
supply system are set. In the TRNSYS model, the indoor temperature must not fall below $15^{\circ} \mathrm{C}$ and the heat pump output must not exceed $800 \mathrm{~kW}$ during the heating season. During the cooling season, the internal temperature of the plant factory must not exceed $34^{\circ} \mathrm{C}$, which will affect the normal growth of the plants. In order to derive the simulated energy consumption values for cooling and heating and to assess the heating effect of the ground water-source heat pump energy supply system, the Type 65 printer module of TRNSYS outputs the simulated cooling and heating loads and the plant factory internal temperature for a typical year. The typical year hourly heat loads for the plant factory of ground water-source heat pump energy supply system are shown in Figure 3.

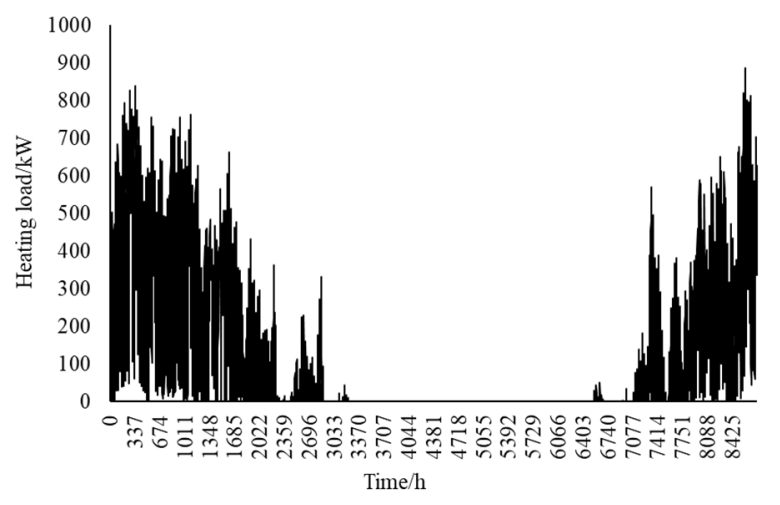

Figure 3. Hourly heat load of plant factory energy supply system in a typical meteorological year

As can be seen from Figure 3, the plant factory no longer requires heating from the energy supply system at approximately hour 2887 and continues to do so until hour 7150 when heating is restarted. The simulation shows that the plant factory is provided with heat from January to April and in November and December of the year. However, due to the presence of thermal curtains and other heating equipment that do not require a ground source heat pump system, as well as the cost-saving shutdown of the ground source heat pump system when the heat load is low, the actual heating period for the plant factory is generally from December to March, with November and April being the transitional heating period, where there is a large temperature difference between day and night on certain days, and theoretically a need for cooling during the day and heating at night. To reduce the cost of starting and stopping the heating system as well as the complexity of the control, the plant factory is supplied with a small cooling and heating load, and the greenhouse is allowed to fluctuate above the set upper and lower temperature limits, so the actual heating energy consumption in November and April is less than the simulated value. The monthly hour-by-hour heat load is integrated and the months with an average heat load of less than $40 \mathrm{kw}$ are removed to obtain the annual ground water-source heat pump heating energy consumption for the plant factory, calculated for January to March and November to December only, totaling 3530.84 GJ.

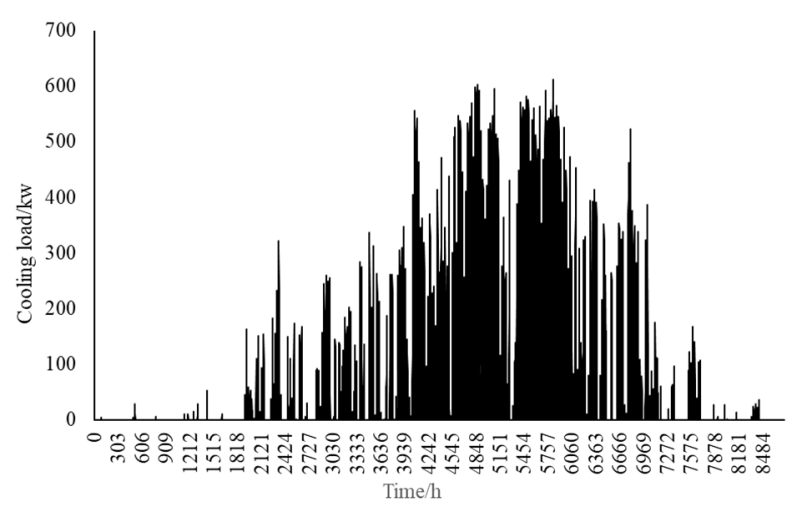

Figure 4. Hourly cooling load of plant factory energy supply system in a typical meteorological year

Hourly cooling load of plant factory energy supply system in a typical meteorological year is shown in Figure 4. Cooling is required in the plant factory from about $2002 \mathrm{~h}$ until about $7080 \mathrm{~h}$. The cooling season for the plant factory is from April to October, where the cooling load in April and October is low due to the presence of open windows for ventilation, wet curtain fans, and spray cooling systems, which can be cooled by other methods. April and October are the transitional heating and cooling seasons. The monthly hour-by-hour cooling load is integrated and the months with an average heat load of less than $40 \mathrm{kw}$ are removed to obtain the annual ground water-source heat pump cooling energy consumption for the plant factory, calculated for June to September only, totaling $1126.24 \mathrm{GJ}$.

To assess the effect of the ground water-source heat pump system, simulated values of the internal temperatures of seven greenhouses within a typical year were output and the results are shown in Figure 5.

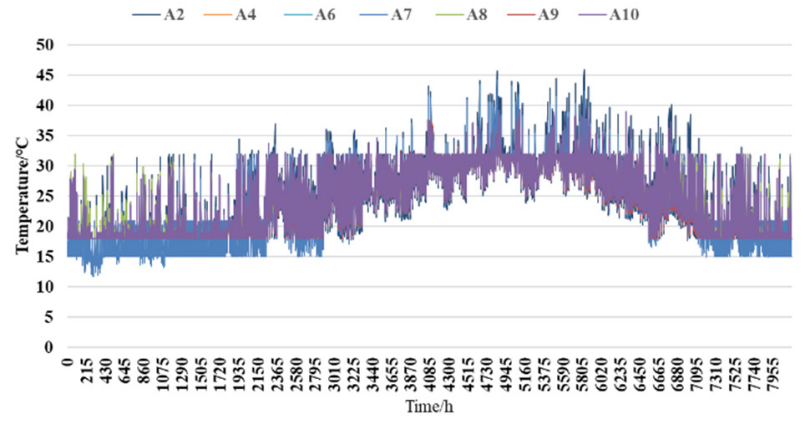

Figure 5. Simulation value of internal temperature of seven greenhouses of plant factory in a typical meteorological year

As can be seen from Figure 5, the ground water-source heat pump system can ensure that the internal temperature of each greenhouse in the plant factory is between $15^{\circ} \mathrm{C}$ and $34^{\circ} \mathrm{C}$, but there are also cases where the internal temperature of each greenhouse exceeds this range. During the heating season, the outdoor temperature is too low, resulting in an excessive heat load, and the output of the energy supply system does not meet the heating requirements of the greenhouse, resulting in the internal temperature falling below $15^{\circ} \mathrm{C}$, but basically not below $12^{\circ} \mathrm{C}$. In summer, the cooling capacity of the system does not meet the cooling requirements of the greenhouse, 
especially in July and August, even if the energy supply system is running at full capacity, the plant factory will reach over $40^{\circ} \mathrm{C}$, which seriously affects plant growth. The high-temperature season is not suitable for plant production in terms of the energy economy. After optimization, the plant factory can be operated as follows: during the year, the operation stops in July and August, and planting only takes place between September and June, a period of 10 months. This reasonably avoids periods of extreme heat and reduces summer cooling costs. Screening the data in Figure 5, the indoor temperature of each greenhouse in the plant factory excluding the July and August temperatures, the maximum value of the average temperature of the seven greenhouses in the remaining months is $36.85^{\circ} \mathrm{C}$, which is within the range that ensures the survival of the plants. When the ground water-source heat pump system is switched off in July and August, the cooling energy consumption in a typical meteorological year is reduced by $56 \%$ to $767.48 \mathrm{GJ}$, i.e. $213,188.9 \mathrm{~kW}-\mathrm{h}$. Based on the peak hour electricity price of $0.752 \mathrm{RMB} /(\mathrm{kW}-\mathrm{h})$ for agricultural electricity in Shanghai, the annual operating cost can be reduced by 160,318.05 RMB.

\section{Conclusion}

This paper establishes a TRNSYS simulation model for the ground water-source heat pump system of the plant factory. The results yielded the energy consumption of the heating season of $2315.16 \mathrm{GJ}$, with a simulation accuracy of over $99 \%$. The TRNSYS model can be used for yearround energy consumption simulation. The simulation results indicate that the ground water-source heat pump system provides 3530.84 GJ of heat and 1126.24 GJ of cooling to the plant factory throughout the year. In winter the plant factory can keep the indoor temperature within the normal range in most cases, while in summer the temperature can reach above $40^{\circ} \mathrm{C}$, which seriously affects plant growth. In terms of energy consumption economy, the plant factory should avoid high-temperature extremes. When the ground water-source heat pump energy supply system is switched off in July and August and the plant factory stops running, the total annual cooling energy consumption can be saved by $56 \%$, totalling $767.48 \mathrm{GJ}$ and reducing the running cost by 160,318.05 RMB, which has good economic benefits.

\section{Acknowledgments}

This work was financially supported by National Key Research and Development Program of China (2020YFD1100402-5).

\section{References}

1. Han J, Cui M, Chen J, et al. Analysis of thermal performance and economy of ground source heat pump system: a case study of the large building[J]. Geothermics, 2021, 89:101929.
2. Qu Yunxia, Zhang Linhua, Fang Zhaohong, et al. The study and design on ground water heat pumps[J]. Renewable Energy Resource, 2002(6): 11-14.

3. Van Ooteghem R J C. Optimal Control Design for a Solar Greenhouse[D]. Wageningen: Wageningen University, 2007.

4. Chai Lilong, Ma Chengwei, Ni J Q. Performance evaluation of ground source heat pump system for greenhouse heating in northern China[J]. Biosystems Engineering, 2012, 111(1): 107-117.

5. Chai Lilong, Ma Chengwei, Zhang Yi, et al. Energy consumption and economic analysis of ground source heat pump used in greenhouse in Beijing[J]. Transactions of the Chinese Society of Agricultural Engineering (Transactions of the CSAE), 2010, 26(3): 249-254.

6. Mehmet Esen, Tahsin Yuksel. Experimental evaluation of using various renewable energy sources for heating a greenhouse $[\mathrm{J}]$. Energy and Buildings, 2013, 65: 340-351.

7. Chai Lilong, Ma Chengwei. Performance and carbon emission analysis on glass-covering greenhouse heating with ground source heat pump technology[J]. Transactions of the Chinese Society for Agricultural Machinery, 2012, 43(1): 185-191.

8. Safa A A, Fung A S, Kumar R. Heating and cooling performance characterisation of ground source heat pump system by testing and TRNSYS simulation[J]. Renewable Energy, 2015, 83:565-575.

9. Andrew D Chiasson, Cenk Yavuzturk. Assessment of the viability of hybrid geothermal heat pump system with solar thermal collector[S]. ASHRAE Transactions, 2003, 109(2) :487-500.

10. Shi Huixian, Xu Detian, Zhu Hongguang, et al. T R NSYS Simulation of Integrated Solar and Ground Source Heat Pump for Biogas Digester Heating System[J]. Transactions of the Chinese Society of Agricultural Engineering (Transactions of the CSAE),2017,48(08):288-295. 